\title{
BMJ Open Effect of COVID-19 on smoking cessation outcomes in a large primary care treatment programme: an observational study
}

\author{
Scott Veldhuizen (D) , ${ }^{1}$ Peter Selby, ${ }^{1,2,3,4,5}$ Benjamin Wong, ${ }^{1}$ Laurie Zawertailo (D) ${ }^{1,2,6}$
}

To cite: Veldhuizen S, Selby $P$, Wong B, et al. Effect of COVID-19 on smoking cessation outcomes in a large primary care treatment programme: an observational study. BMJ Open 2021;11:e053075. doi:10.1136/ bmjopen-2021-053075

- Prepublication history and additional supplemental material for this paper are available online. To view these files, please visit the journal online. (http://dx.doi.org/10.1136/ bmjopen-2021-053075)

Received 05 May 2021 Accepted 13 August 2021
Check for updates

(C) Author(s) (or their employer(s)) 2021. Re-use permitted under CC BY-NC. No commercial re-use. See rights and permissions. Published by BMJ.

For numbered affiliations see end of article.

Correspondence to Dr Scott Veldhuizen; scott.r.veldhuizen@gmail.com

\section{ABSTRACT}

Objectives The COVID-19 pandemic has changed patterns of smoking, other substance use and other health-related behaviours, leading to a virtualisation of non-urgent medical care. In this study, we examine associated changes in outcomes of smoking-cessation treatment.

Design Observational study.

Setting Data are drawn from 221 physician-led primary care practices participating in a smoking cessation program in Ontario, Canada.

Participants 43509 patients (53\% female), comprising 35385 historical controls, 6109 people enrolled before the pandemic and followed up during it, and 1815 people enrolled after the pandemic began.

Intervention Nicotine-replacement therapy with counselling.

Primary outcome measure 7-day self-reported abstinence from cigarettes at a follow-up survey 6 months after entry.

Results For people followed up in the 6 months (6M) after the pandemic began, quit probability declined with date of enrolment. Predicted probabilities were $31.2 \%(95 \% \mathrm{Cl}$ $30.0 \%$ to $32.5 \%$ ) for people enrolled in smoking cessation treatment 6 months prior to the emergency declaration and followed up immediately after the state of emergency was declared, and $24.1 \%$ (95\% Cl $22.1 \%$ to $26.2 \%$ ) for those enrolled in treatment immediately before the emergency declaration and followed up 6M later (difference $=-6.5 \%$, $95 \% \mathrm{Cl}-9.0 \%$ to $-3.9 \%$ ). Seasonality and total treatment use did not explain this decline.

Conclusion The probability of successful smoking cessation following treatment fell during the pandemic, with the decline consistent with an effect of 'exposure' to the pandemic-era environment. As many changes happened simultaneously, specific causes cannot be identified; however, the possibility that virtual care has been less effective than in-person treatment should be explored.

\section{INTRODUCTION}

The reported effects of the COVID-19 pandemic on tobacco addiction and its treatment are complex and sometimes contradictory. Survey data suggest that smokers in some countries have increased their use of
Strengths and limitations of this study

- This is the first large study to evaluate changes in outcomes of smoking cessation treatment during the COVID-19 pandemic.

- The large sample size and the treatment of time effects made it possible to measure changes in outcomes with good precision.

- The decrease in quit probability we observed occurred within the group of people who enrolled in the prepandemic period and is therefore unlikely to result from case-mix changes linked to the pandemic itself.

- Treatment in participating clinics changed at the beginning of the pandemic; it is therefore unclear whether changes are due to changes in the care provided or to the wider context of the pandemic.

tobacco since the pandemic began ${ }^{1-3}$ and also that interest in quitting ${ }^{45}$ (but see also ref 6), quit attempts, and successful cessation have risen. ${ }^{7}$ Heavy drinking and high psychological distress, both intimately linked with tobacco use, also seem to have become more prevalent in the COVID-19 era, ${ }^{89}$ and there is some evidence that the same may be true of substance use disorders in general, partly due to relapse among former users. ${ }^{10}$

Some of these changes are likely to be due to contextual changes. Public health restrictions have reduced social contact and mobility, ${ }^{11}$ while job losses and the shift to remote work may have blunted the effects of smoking restrictions in workplaces and public spaces. Changes in smoking behaviour may also be influenced by reported associations between COVID-19 and smoking, ${ }^{12}$ including suggestions that smoking may protect against infection ${ }^{13}$ but is also associated with more severe illness. ${ }^{14} 15$

The pandemic has also had marked effects on medical care. Public health messaging has encouraged people to delay non-urgent 
care, and providers have had to restrict contacts with and among patients, to acquire and use personal protective equipment, and to divert resources to test and treat potential COVID-19 cases. In Ontario, Canada, which is the region of interest in this report, total primary care visits fell sharply early in the pandemic, and in-person contacts were rapidly displaced by virtual care. ${ }^{16}$

Although one small study has suggested that abstinence did not change during the pandemic for people treated previously, ${ }^{17}$ the net effect of pandemic era changes on the effectiveness of care for smoking cessation is largely unknown. Given the global nature of the pandemic and the importance of tobacco use as a public health issue, this is a question of some urgency. In this study, we examine changes during the pandemic period in the probability of achieving abstinence from cigarettes among participants in a long-running primary care smoking cessation treatment programme. To our knowledge, this is the earliest attempt to understand the effects of the pandemic on the outcomes of formal treatment for tobacco addiction.

\section{METHODS}

\section{Design}

We use longitudinal data from a clinical programme to study changes over time in treatment outcomes before and during the COVID-19 pandemic. Our outcome is self-reported past 7-day abstinence from cigarettes at the 6-month follow-up, with abstinence defined as a 'no' response to the question, 'have you smoked a cigarette, even a puff, in the last 7 days'. We consider changes over time in the probability of a 'no' response to this question for three groups of participants: (1) those enrolled and followed up before the state of emergency declaration on 17 March 2020 ( $n=35$ 385); (2) those enrolling before this time but followed up after it $(\mathrm{n}=6109)$; and (3) those enrolling after 17 March $2020(n=1815)$.

\section{Setting}

The Smoking Treatment for Ontario Patients (STOP) programme provides free counselling and nicotine replacement therapy (NRT) ${ }^{18}$ with direct care provided principally by nurses and pharmacists. We analysed data from 226 family health teams that participated in the programme during the study period. Family health teams are physician-led primary care practices with defined rosters of patients. Participants are eligible to receive up to 26 weeks of NRT over a 1-year period and are typically seen every 2-4 weeks. Smoking status and heaviness of smoking, as well as other clinically relevant data, are ascertained by self-report. Some sites also perform carbon monoxide or cotinine verification at clinical contacts, but this is not a feature of the core programme.

Ontario family health teams largely transitioned to remote care in the early months of the pandemic. ${ }^{16}$ However, each STOP clinic responded to the crisis independently and in ways that varied over time. Clinic adaptations were discussed in a teleconference with representatives from 99 participating organisations in June 2020. Broadly, providers reduced in-person clinic visits, performed consultations by phone or videoconference where possible, and either shipped NRT to participants or arranged for distanced pickup.

\section{Data}

STOP participants are followed up by email at 3 months and by email, phone or at a clinical contact at 6 months and 12 months after baseline. We use the 6-month follow-up because this is the programme's primary reported outcome, and efforts to contact participants are most intensive (and follow-up rates highest) at this time. As $85 \%-90 \%$ of follow-ups are done remotely, objective verification of smoking status using biochemical validation was not feasible. However, the validity of self-reported smoking status has generally been shown to be good. ${ }^{19} 20$ The general follow-up approach did not change during the pandemic, with most participants continuing to be reached by phone.

\section{Context}

In Ontario, substantial numbers of COVID-19 cases were first detected in March 2020. ${ }^{21}$ The provincial government declared a state of emergency on 17 March 2020, mandating the closure of schools and many business and indoor public spaces. Following the state of emergency declaration, STOP enrolments immediately fell by $70 \%$. By January 2021, they had recovered to $30 \%$ below normal levels. Changes in restrictions after March 2020 had no clear effects on enrolments. We use the state of emergency declaration on 17 March as the primary break-point in our analysis, as it marks the beginning of public health restrictions and, more approximately, of the epidemic itself. We refer to times before and after this date as the 'prepandemic' and 'pandemic' periods, respectively.

\section{Participants}

We included participants enrolled from 11 April 2016, when the STOP surveys were expanded to include several important variables, to 16 July 2020 , which is the latest date for which 6-month follow-ups were available. These follow-ups were done between 11 November 2016 and 16 February 2021. From the 58292 such enrolments, we removed 4314 (7.4\%) people who were not daily smokers at baseline and $521(0.9 \%)$ without recorded clinical visits. People are also allowed to re-enrol in STOP after their full 1-year treatment eligibility period has expired. We used probabilistic deduplication to identify repeat enrolments and kept only the most recent enrolment for each person. This meant removing a further $9948(17.1 \%)$ records, almost all of which $(9555 ; 96 \%)$ were followed up in the prepandemic period. The final analysis sample included 43509 unique participants from 226 clinics (see online supplemental file 1). 


\section{Analytic approach}

To understand the effects of pandemic-related changes on smoking cessation treatment outcomes, we conducted an individual-level analysis of change in the probability of successful cessation by date of enrolment. For enrolments in the 6 months $(6 \mathrm{M})$ before the pandemic, we interpret change over time primarily as a continuous measure of exposure to the pandemic environment. People enrolling at the beginning of this period will have experienced the pandemic for only a short time before their follow-up, and as the total length of treatment is usually less than 6 months,${ }^{21}$ only a few will have received treatment during the pandemic. Conversely, those enrolling just before the state of emergency declaration will have usually made their quit attempt(s), and received most of their treatment, after pandemic-related restrictions were imposed.

\section{Patient involvement}

This was a secondary analysis of programme data, without direct involvement of patients in the design of the study or the interpretation of results.

\section{Ethics approval}

The STOP Program is funded by the Ontario Ministry of Health and Long-term Care. Participants provided informed, written consent for use of data for research at the time of the baseline interview.

\section{Analysis}

We first produced descriptive statistics. We then fit a piecewise mixed-effects logistic regression model that estimates one slope for date of enrolment for enrolments from 11 April 2016 to 16 September 2019 and another for those from 17 September 2019 to 17 March 2020. To test for changes after this date, we initially included both another slope and an indicator variable that was one for people who enrolled after 17 March 2020 and 0 otherwise. The indicator captures any overall change for these participants, while we included a slope to explore the possibility of further gradual change.

This model allows for different time effects for each of our three groups of participants: those enrolled and followed up before the state of emergency declaration; those enrolled before this time but followed up after it; and those enrolled after this point. As noted, it is change by date of enrolment within the second group that is of greatest interest. We included a random intercept for study site and evaluated time effects for linearity by examining monthly means. To obtain absolute adjusted differences (AADs) between pairs of time points, we used postestimation procedures on estimated marginal means.

We adjusted for possible changes in case-mix by including a set of baseline participant characteristics, selected a priori, that are known to be associated with treatment outcome. These were: age, sex/gender, cigarettes per day, time to first cigarette after waking, previous lifetime quit attempts, motivation to quit (1-10), confidence in ability to quit (1-10) and lifetime diagnosis of a physical (heart disease, cancer, stroke, diabetes or chronic obstructive pulmonary disease (COPD), mental health (anxiety, depression, bipolar disorder or schizophrenia) or non-tobacco substance-related condition (drug use disorder or alcohol use disorder).

To examine the possibility that any changes in outcome were associated with changes in the type or amount of treatment used, we fit a further model that included: (1) the total number of clinical visits attended in the first $6 \mathrm{M}$ of treatment; (2) the type of NRT initially dispensed (no NRT, short-acting forms only, patch only or short-acting and patch in combination); and (3) the total number of weeks of NRT provided.

Finally, previous work with STOP data has shown that treatment outcomes show modest seasonal variation. ${ }^{22}$ It is not clear, however, that the factors underlying seasonal differences continued to operate in the same way during the pandemic, which disrupted holiday taking, socialising and other activities. As a result, we treated this question as a sensitivity analysis and fit a further model including dummy-coded month of year. We used Stata V.16 for all analyses. $^{23}$

\section{Missing data}

Most baseline variables include some missing data (table 1). The outcome was also available only for 27541 $(64 \%)$ participants who completed the $6 \mathrm{M}$ follow-up survey. This level of completeness compares favourably with other large, observational studies of smoking cessation treatment (eg, refs 24 25). We addressed missing data using multiple imputation with chained equations, with 50 imputed datasets. We included all variables from our substantive models, including treatment variables. As auxiliary variables, we included quit status at $3 \mathrm{M}$ follow-up (where available), quit status at the last clinical contact before $6 \mathrm{M}$ and the number of previous enrolments, if any. We do not impute missing outcomes to 'smoking', because this would bias the quit proportion downwards and would also bias effects of any variables, including time, that are associated with loss to follow-up. ${ }^{26} 27$

Multiple imputation reduces bias by taking into account observed associations between non-response and the variables measured but does not exclude the possibility that quit status itself is independently associated with response at follow-up. This is a potential concern for our analysis of change over time, because our follow-up rate rose from $61 \%$ before the pandemic to $75 \%$ for people followed up after it began. This was partly due to a higher response rate for phone surveys and partly because efforts to reach participants were intensified. However, the follow-up rate after the pandemic began was approximately constant, and it is variation in outcomes for these participants that are of primary interest.

\section{RESULTS}

Descriptive statistics are shown in table 1 , and the overall proportion of participants successfully quitting, by month of enrolment, is shown in figure 1. 
Table 1 Descriptive statistics

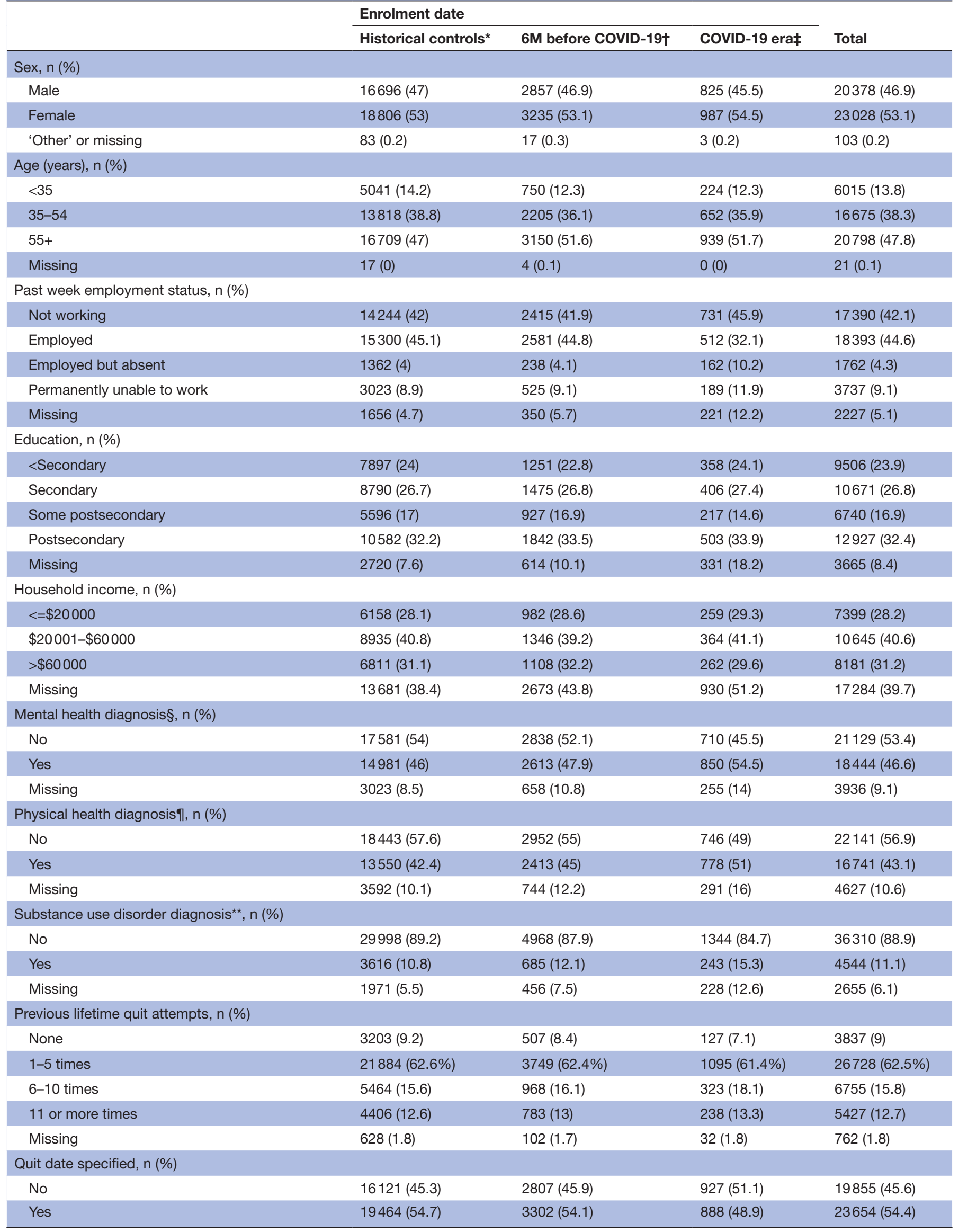


Table 1 Continued

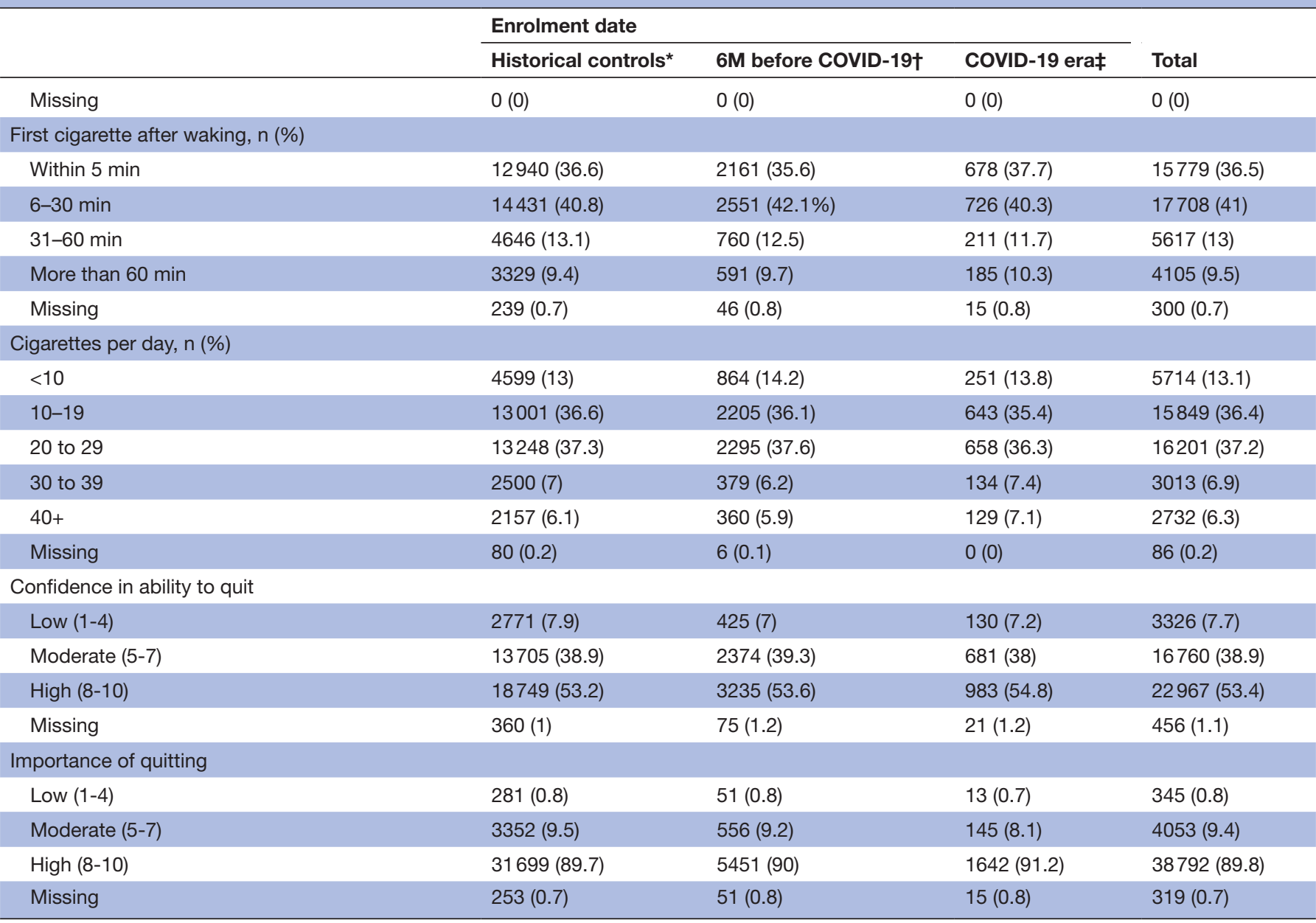

*11 April 2016-16 September 2019.

†17 September 2019-16 March 2020.

$\ddagger 17$ March 2020-16 July 2020.

§Lifetime diagnosis of depression, anxiety, bipolar disorder or schizophrenia.

ILifetime diagnosis of heart disease, stroke, diabetes, cancer or chronic obstructive pulmonary disease.

${ }^{*}$ Lifetime diagnosis of non-tobacco substance use disorder.

$6 \mathrm{M}, 6$ months.

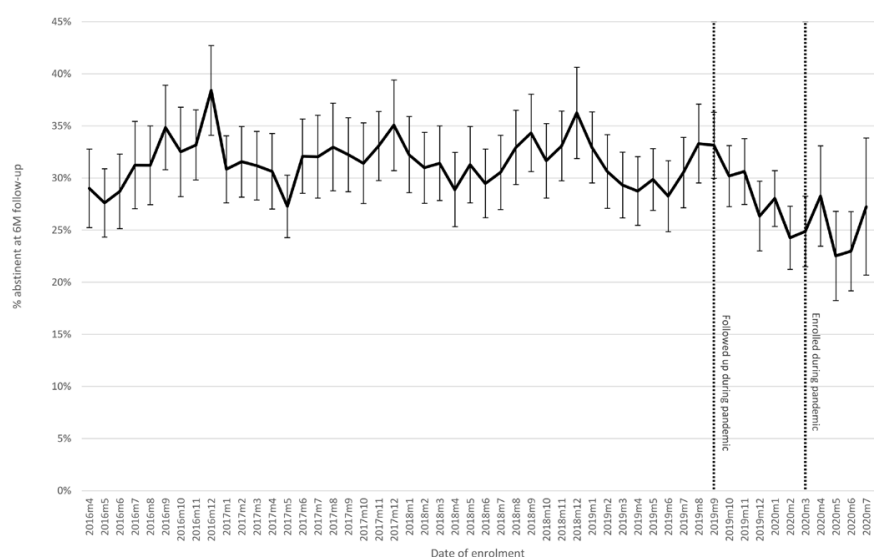

Figure 1 Proportion of patients abstinent from cigarettes for 7 days at 6-month follow-up, by month of enrolment, with $95 \% \mathrm{Cl}$.
Table 2 Time terms from final mixed-effects logistic regression models

\begin{tabular}{|c|c|c|}
\hline & OR $(95 \% \mathrm{Cl})$ & $P$ value \\
\hline \multicolumn{3}{|l|}{ Main model } \\
\hline $\begin{array}{l}\text { Time: } 11 \text { April 2016-16 } \\
\text { September } 2019^{\star}\end{array}$ & 1.000 (0.997 to 1.002$)$ & 0.77 \\
\hline $\begin{array}{l}\text { Time: } 17 \text { September 2019-17 } \\
\text { March } 2020^{\star}\end{array}$ & 0.940 (0.918 to 0.962$)$ & $<0.001$ \\
\hline Post-17 March 2020 & 1.09 (0.93 to 1.28$)$ & 0.28 \\
\hline \multicolumn{3}{|l|}{ With seasonality adjustment } \\
\hline $\begin{array}{l}\text { Time: } 11 \text { April } 2016-16 \\
\text { September } 2019^{\star}\end{array}$ & 1.000 (0.998 to 1.002$)$ & 0.98 \\
\hline $\begin{array}{l}\text { Time: } 17 \text { September 2019-17 } \\
\text { March } 2020^{\star}\end{array}$ & 0.942 (0.919 to 0.965$)$ & $<0.001$ \\
\hline Post-17 March 2020 & $1.22(1.02$ to 1.46$)$ & 0.03 \\
\hline
\end{tabular}

*Per 30 days. 
$34:$

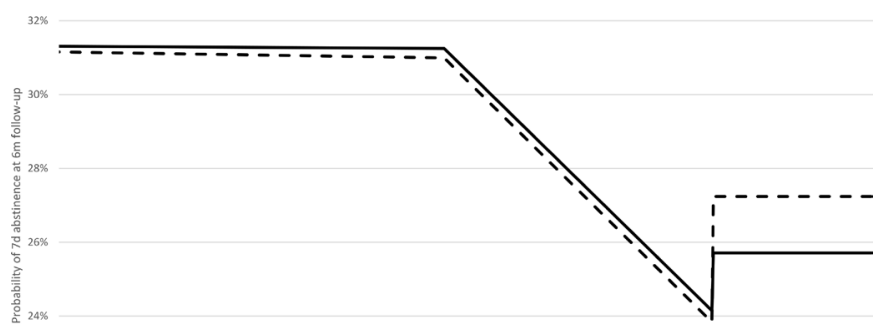

$22 \%$

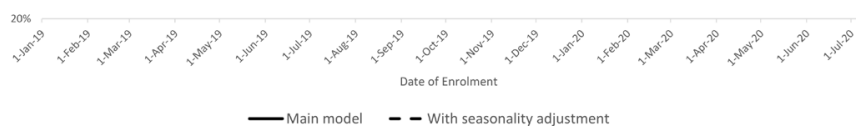

Figure 2 Predicted probability of being abstinent from cigarettes for 7 days at 6 -month follow-up by date of enrolment. Solid line shows results from primary model, dotted line shows results adjusting for seasonality.

Model results are shown in table 2, and the corresponding marginal predictions are shown in figure 2. From the initial model, we removed the slope term for postpandemic enrolments, number of clinical visits, type of NRT, and weeks of NRT dispensed, all of which were non-significant and did not meaningfully change estimates of change over time.

In the final model, there was no change over time in the probability of cessation for people who were followed up before the pandemic. For people who enrolled prepandemic and were followed up during it, however, the probability of cessation fell with date of enrolment. Predicted probabilities were $31.2 \%$ (95\% CI $30.0 \%$ to $32.5 \%$ ) for people enrolled 6 months prior to the emergency declaration and followed up immediately before the state of emergency was declared and $24.1 \%$ (95\% CI $22.1 \%$ to $26.2 \%$ ) for those enrolled in treatment immediately before the emergency declaration and followed up $6 \mathrm{M}$ later. This is a decrease of $6.5 \%$ (95\% CI $3.9 \%$ to $9.0 \%$ ).

Adjusting for seasonality did not meaningfully change effects for prepandemic enrolments (figure 2). However, this adjustment did increase the coefficient for enrolment during the pandemic period and lowered the corresponding $\mathrm{p}$ value to 0.03 . As this effect was not significant in our main model, the evidence for a change in quit success for these enrolments is ambiguous. Even in the seasonality adjusted model, however, the predicted probability of quitting smoking remained lower for pandemic-era enrolments than it was for people who enrolled before the pandemic began (AAD $=-3.8 \%, 95 \% \mathrm{CI}-6.5 \%$ to $-1.0 \%$ ).

\section{DISCUSSION}

In this large, primary care smoking cessation programme, the COVID-19 pandemic was associated with a clinically meaningful decrease in the proportion of patients who quit successfully. The quit probability fell linearly with date of enrolment, which is consistent with an effect of 'exposure' to the pandemic environment: people who spent more of their follow-up period, and received more of their treatment, during the pandemic period were less likely to quit smoking. This change was not accounted for by seasonal variation, by changes in the known characteristics of enrolling participants or by differences in the type or amount of treatment provided. For people enrolled after the state of emergency, the probability of cessation may have increased slightly, but neither varied strongly nor returned to its prepandemic level, which is consistent with the continued operation of factors associated with the pandemic.

Ontario's public health measures changed over the study period, and beliefs and behaviours of programme participants may also have varied. The probability of successful smoking cessation, however, declined approximately linearly with enrolment date. This is probably because outcomes reflect the net effects of all influences over the 6-month period and will not have been sensitive to small or short-term contextual differences. Chance variation and possible seasonal differences also make it difficult to discern small probability variations within this time.

It is not possible to confidently link poorer treatment outcomes to specific causes, because the pandemic brought change in many areas simultaneously. Of potential causes, however, we can usefully distinguish between:

(1) changes related to the wider pandemic context and (2) changes in the care provided. As noted, some data suggest that psychological distress and substance use have increased during the pandemic, ${ }^{89}$ and this may have made quitting smoking more difficult for some people. Population survey data from other countries generally do not suggest that cessation rates fell, ${ }^{7}$ but the evidence on this question is limited, and what is true of the wider population may not be true of smokers in treatment. The effects of contextual factors on treatment outcomes therefore remain unclear.

Despite the difficulty of disentangling causal effects, it is important to consider possible impacts of changes in care provision. In STOP, there were no pandemicrelated disruptions at the programme level: delivery of NRT supplies to each clinic continued uninterrupted, we placed no restrictions on conduct of remote visits or enrolment of new participants using verbal consent procedures, and our model results show that the amount of treatment received did not meaningfully change estimates of change over time. However, as noted, care in Ontario family health teams (FHTs) was rapidly virtualised following the beginning of the pandemic. ${ }^{16}$ Virtual care may have changed the nature of counselling, with group therapy, for example, becoming a technological challenge. Provision of NRT may also have become less timely, and less tangible influences, such as immediacy and engagement, may also be relevant.

It is therefore possible that the decrease in quit rate is due to virtual treatment for smoking cessation being less 
effective than in-person care. There is surprisingly little evidence on this question. The overall effectiveness of remote care for smoking cessation, in the form of telephone quitlines, ${ }^{28} 29$ is well established. ${ }^{30} 31$ However, very few trials have directly compared any form of remote care directly to in-person treatment. ${ }^{32} 33$ One such non-inferiority trial from Japan found no difference in outcomes but was not powered to detect small differences and provided an intervention that may not be entirely comparable with those offered during the pandemic by smoking cessation clinics. ${ }^{34}$ Studies on alcohol ${ }^{35}$ and opioid use ${ }^{36}$ disorders have also failed to find differences between in-person and virtual care, but the applicability of this research to tobacco cessation is uncertain, and sample sizes were again relatively small. Moreover, the pandemic obliged STOP providers to transition very rapidly to remote care without extensive preparation or training, and this may, in some cases, have made it difficult to provide optimal care.

A further possibility is that the pandemic disrupted existing treatment episodes, with participants accustomed to in-person treatment having to adjust to remote care. In this case, it would not be the new care approaches themselves, but the transition to them, that is important. If this were the case, we would expect to see an increase in quit probability among people enrolling after the pandemic began, as they received all treatment after the shift to remote care had occurred. Our results are ambiguous on this question, due to the uncertain influence of seasonal variation. They do show, however, that the quit probability for these patients did not return to prepandemic levels. Disruptions to ongoing care therefore cannot entirely explain the change in quit success, and it is likely that the factors underlying the poorer outcomes among preCOVID-19 enrolments continued to affect people who enrolled after the state of emergency.

Although STOP is a single programme, it was delivered in 226 team-based primary care practices across Ontario during the study period, and changes in processes and protocols were implemented independently at each clinic. The experience of Ontario during this period was also fairly similar to those of many other developed world jurisdictions, in terms of the epidemiology of COVID-19 and the public health restrictions that were imposed. We therefore believe that results will be relevant to other contexts. Our findings also suggest that the wider question of the effectiveness of remote treatment in primary care deserves close attention.

\section{Limitations}

We lack detailed information about how individual clinics adapted to COVID-19. It is also possible that people enrolling during the pandemic differed from those enrolling earlier on unmeasured variables. However, this does not affect the primary results, which rest on time effects for earlier enrolments. A substantial proportion of participants also did not complete their $6 \mathrm{M}$ follow-up. Although we have tried to account for missingness in our analysis, it is conceivable that there remained uncaptured associations between treatment outcome and other variables. As noted, our follow-up rate also increased for pandemic-era follow-ups. However, this cannot explain change in outcomes over time within the group followed up during this period, because the follow-up rate over this period was approximately constant.

\section{CONCLUSION}

The STOP model ensured that smoking cessation treatment continued to be provided in primary care during the COVID-19 pandemic, and this treatment did remain generally effective. However, the proportion of participants who quit successfully declined meaningfully during this time. As the number of people receiving this care was also reduced by public health restrictions, reduced smoking cessation through formal treatment can be numbered among the important negative secondary effects of the pandemic. There is a need for research on the effectiveness and further optimisation of virtual care for smoking cessation.

\section{Author affiliations}

${ }^{1}$ Nicotine Dependence Service, Centre for Addiction and Mental Health, Toronto, Ontario, Canada

${ }^{2}$ Department of Family and Community Medicine, University of Toronto Temerty Faculty of Medicine, Toronto, Ontario, Canada

${ }^{3}$ Campbell Family Mental Health Research Institute, Centre for Addiction and Mental Health, Toronto, Ontario, Canada

${ }^{4}$ Dalla Lana School of Public Health, University of Toronto, Toronto, Ontario, Canada

${ }^{5}$ Department of Psychiatry, University of Toronto, Toronto, Ontario, Canada

${ }^{6}$ Department of Pharmacology and Toxicology, University of Toronto Faculty of Medicine, Toronto, Ontario, Canada

Contributors SV designed and performed the analysis and drafted and revised the manuscript. He is guarantor. BW assisted with the analysis of the data and revised the paper. LZ and PS initiated and manage the Smoking Treatment for Ontario Patients programme, supervised data collection, and drafted and revised the paper.

Funding This work was supported by the Ontario Ministry of Health (grant number HLTC5047FL). PS is also supported by the Centre for Addiction and Mental Health and by the Clinician Scientist programprogramme at Department of Family and Community Medicine, University of Toronto.

Disclaimer The funder had no role in study design, data collection and analysis, interpretation of findings, preparation of this manuscript or decision to submit for publication.

Competing interests The authors have no conflicts of interest to declare. However, PS has the following general disclosures to report: grants and/or salary and/or research support from the Centre for Addiction and Mental Health, Health Canada, Ontario Ministry of Health and Long-term care, Canadian Institutes of Health Research, Canadian Centre on Substance Use and Addiction, Public Health Agency of Canada, Ontario Lung Association, Medical Psychiatry Alliance, Extensions for Community Healthcare Outcomes, Canadian Cancer Society Research Institute, Cancer Care Ontario, Ontario Institute for Cancer Research, Ontario Brain Institute, McLaughlin Centre, Academic Health Sciences Centre, Workplace Safety and Insurance Board, National Institutes of Health and the Association of Faculties of Medicine of Canada. PS also reports receiving funding and/or honoraria from the following commercial organisations: Pfizer Inc/Canada, Shoppers Drug Mart, Bhasin Consulting Fund Inc, Patient-CenteredCentred Outcomes Research Institute, ABBVie and Bristol-Myers Squibb. Furthermore, PS reports receiving consulting fees from Pfizer Inc/Canada, Evidera Inc, Johnson \& Johnson Group of Companies, Medcan Clinic, Inflexxion Inc, V-CC Systems Inc, MedPlan Communications, Kataka Medical Communications, Miller Medical Communications, Nvision Insight Group and Sun Life Financial. Through an open tender process, Johnson \& Johnson, Novartis, and Pfizer Inc are vendors of record for providing smoking cessation pharmacotherapy, 
free or discounted, for research studies in which PS is the principal investigator or coinvestigator.

Patient consent for publication Not required.

Ethics approval Procedures were approved by the Research Ethics Board at the Centre for Addiction and Mental Health (protocol numbers 058-2011 and 154-2012).

Provenance and peer review Not commissioned; externally peer reviewed.

Data availability statement Data are available upon reasonable request. Requests for access to anonymised patient-level data will be considered in consultation with the supervising privacy and ethics bodies. Enquiries should be made to the corresponding author.

Supplemental material This content has been supplied by the author(s). It has not been vetted by BMJ Publishing Group Limited (BMJ) and may not have been peer-reviewed. Any opinions or recommendations discussed are solely those of the author(s) and are not endorsed by BMJ. BMJ disclaims all liability and responsibility arising from any reliance placed on the content. Where the content includes any translated material, BMJ does not warrant the accuracy and reliability of the translations (including but not limited to local regulations, clinical guidelines, terminology, drug names and drug dosages), and is not responsible for any error and/or omissions arising from translation and adaptation or otherwise.

Open access This is an open access article distributed in accordance with the Creative Commons Attribution Non Commercial (CC BY-NC 4.0) license, which permits others to distribute, remix, adapt, build upon this work non-commercially, and license their derivative works on different terms, provided the original work is properly cited, appropriate credit is given, any changes made indicated, and the use is non-commercial. See: http://creativecommons.org/licenses/by-nc/4.0/.

\section{ORCID iDs}

Scott Veldhuizen http://orcid.org/0000-0003-3969-2756

Laurie Zawertailo http://orcid.org/0000-0002-4547-1565

\section{REFERENCES}

1 Rolland B, Haesebaert F, Zante E, et al. Global changes and factors of increase in caloric/salty food intake, screen use, and substance use during the early COVID-19 containment phase in the general population in France: survey study. JMIR Public Health Surveill 2020;6:e19630.

2 Bommelé J, Hopman P, Hipple Walters B, Walters BH, et al. The double-edged relationship between COVID-19 stress and smoking: implications for smoking cessation. Tob Induc Dis 2020;18.

3 Yach D. Tobacco use patterns in five countries during the COVID-19 Lockdown. Nicotine Tob Res 2020;22:1671-2.

4 Klemperer EM, West JC, Peasley-Miklus C, et al. Change in tobacco and electronic cigarette use and motivation to quit in response to COVID-19. Nicotine Tob Res 2020;22:1662-3.

5 Pettigrew S, Jun M, Roberts I, et al. Preferences for tobacco cessation information and support during Covid-19. J Addict Med 2020;14:e362-5.

6 Heerfordt C, Heerfordt IM. Has there been an increased interest in smoking cessation during the first months of the COVID-19 pandemic? trends study. Public Health 2020;183:6-7.

7 Jackson SE, Garnett C, Shahab L, et al. Association of the COVID-19 lockdown with smoking, drinking and attempts to quit in England: an analysis of 2019-20 data. Addiction 2021;116:1233-44.

8 Pierce M, Hope H, Ford T, et al. Mental health before and during the COVID-19 pandemic: a longitudinal probability sample survey of the UK population. The Lancet Psychiatry 2020;7:883-92.

9 Holland KM, Jones C, Vivolo-Kantor AM, et al. Trends in US emergency department visits for mental health, overdose, and violence outcomes before and during the COVID-19 pandemic. JAMA Psychiatry 2021;78:372.

10 Mallet J, Dubertret C, Le Strat Y. Addictions in the COVID-19 era: current evidence, future perspectives a comprehensive review. Prog Neuropsychopharmacol Biol Psychiatry 2021;106:110070.
11 Warren MS, Skillman SW. Mobility changes in response to COVID-19. arXiv 2020;200314228 https://arxiv.org/pdf/2003.14228.pdf

12 Alla F, Berlin I, Nguyen-Thanh V, et al. Tobacco and COVID-19: a crisis within a crisis? Can J Public Health 2020;111:995-9.

13 van Zyl-Smit RN, Richards G, Leone FT. Tobacco smoking and COVID-19 infection. Lancet Respir Med 2020;8:664-5.

14 Lowe KE, Zein J, Hatipoğlu U, et al. Association of smoking and cumulative pack-year exposure with COVID-19 outcomes in the cleveland clinic COVID-19 registry. JAMA Intern Med 2021;181:709.

15 Patanavanich R, Glantz SA. Smoking is associated with COVID-19 progression: a meta-analysis. Nicotine Tob Res 2020;22:1653-6.

16 Glazier RH, Green ME, Wu FC, et al. Shifts in office and virtual primary care during the early COVID-19 pandemic in Ontario, Canada. CMAJ 2021;193:E200-10.

17 Kayhan Tetik B, Gedik Tekinemre I, Taș S. The effect of the COVID-19 pandemic on smoking cessation success. J Community Health 2021;46:471-5.

18 Stead LF, Perera R, Bullen C, et al. Nicotine replacement therapy for smoking cessation. Cochrane Database Syst Rev 2012;1.

19 Patrick DL, Cheadle A, Thompson DC, et al. The validity of selfreported smoking: a review and meta-analysis. Am J Public Health 1994;84:1086-93.

20 Wong SL, Shields M, Leatherdale S, et al. Assessment of validity of self-reported smoking status. Health Rep 2012;23:47-53.

21 Veldhuizen S, Zawertailo L, Noormohamed A, et al. Treatment use patterns in a large extended-treatment tobacco cessation program: predictors and cost implications. Tob Control 2021;35:tobaccocontrol-2020-056203.

22 Veldhuizen S, Zawertailo L, Ivanova A, et al. Seasonal variation in demand for smoking cessation treatment and clinical outcomes. Nicotine Tob Res 2021;23:976-82.

23 Stata statistical software: release 16 [program]2019College Station, TX

24 Kerkvliet JL, Wey H, Fahrenwald NL. Cessation among state quitline participants with a mental health condition. Nicotine Tob Res 2015; 17:735-41.

25 Nair US, Bell ML, Yuan NP, et al. Associations between comorbid health conditions and quit outcomes among smokers enrolled in a state Quitline, Arizona, 2011-2016. Public Health Rep 2018;133:200-6.

26 Blankers M, Smit ES, van der Pol P, et al. The Missing=smoking assumption: a fallacy in Internet-based smoking cessation trials? Nicotine Tob Res 2016;18:25-33.

27 Barnes SA, Larsen MD, Schroeder D, et al. Missing data assumptions and methods in a smoking cessation study. Addiction 2010;105:431-7.

28 Anderson CM, Zhu S-H. Tobacco quitlines: looking back and looking ahead. Tob Control 2007;16:i81-6.

29 Cummins SE, Bailey L, Campbell S, et al. Tobacco cessation quitlines in North America: a descriptive study. Tob Control 2007;16:i9-15.

30 Zhu S-H, Anderson CM, Tedeschi GJ, et al. Evidence of real-world effectiveness of a telephone quitline for smokers. N Engl J Med 2002;347:1087-93.

31 Lichtenstein E, Zhu S-H, Tedeschi GJ. Smoking cessation quitlines: an underrecognized intervention success story. American Psychologist 2010;65:252-61.

32 Lin Lewei (Allison), Casteel D, Shigekawa E, et al. Telemedicinedelivered treatment interventions for substance use disorders: a systematic review. J Subst Abuse Treat 2019;101:38-49.

33 Byaruhanga J, Wiggers J, Paul CL, et al. Acceptability of real-time video counselling compared to other behavioural interventions for smoking cessation in rural and remote areas. Drug Alcohol Depend 2020;217:108296.

34 Nomura A, Tanigawa T, Muto T, et al. Clinical efficacy of telemedicine compared to face-to-face clinic visits for smoking cessation: multicenter open-label randomized controlled noninferiority trial. $J$ Med Internet Res 2019;21:e13520.

35 King SC, Richner KA, Tuliao AP, et al. A comparison between telehealth and face-to-face delivery of a brief alcohol intervention for college students. Subst Abus 2020;41:501-9.

36 King VL, Brooner RK, Peirce JM, et al. A randomized trial of webbased videoconferencing for substance abuse counseling. J Subst Abuse Treat 2014;46:36-42. 